\title{
PESQUISA PARTICIPANTE EM EDUCAÇÃO AMBIENTAL: A CONSTRUÇÃO DA METODOLOGIA E DO CURRÍCULO NO AMBIENTE ESCOLAR
}

\author{
Eliane de Mello ${ }^{1}$, Paulo Edelvar Corrêa Peres ${ }^{2}$, \\ Vânia Medianeira Flores Costa², Luiz Ernani B. de Araujo² \\ ${ }^{1}$ Especialista em Educação Ambiental - UFSM \\ ${ }^{2}$ Professores do Curso de Especialização em Educação Ambiental da UFSM
}

\section{RESUMO}

Este trabalho procura verificar os efeitos da pesquisa participante na construção do currículo e das práticas pedagógicas em Educação Ambiental na escola Estadual de Ensino Médio Paulo Freire. Destarte, pretende-se desenvolver os seguintes objetivos específicos: discorrer a respeito das concepções de Educação Ambiental defendidas pelos gestores brasileiros; descrever o contexto histórico/social que contribuiu para que a escola optasse pelo uso da metodologia da pesquisa participante e apresentar a visão dos professores que participaram da elaboração do Projeto Político Pedagógico a respeito dos efeitos da pesquisa participante na construção do currículo e das práticas pedagógicas em Educação Ambiental. A pesquisa realizou-se através do método bibliográfico qualitativo. A investigação demonstrou que há uma enorme distância entre o discurso pedagógico e a prática educacional e que mudanças significativas na educação, necessitam do apoio estrutural e financeiro dos gestores. Por outro lado, constatou-se que houve alguns avanços no cotidiano da escola investigada, como por exemplo: a compreensão do conceito de educação ambiental como interdisciplinar, a compreensão da necessidade de se contribuir com a construção da cidadania, a constatação da importância de se conhecer a realidade do aluno, a compreensão da necessidade de contextualizar problemas locais e tentar resolvê-los, a percepção da importância do professor tornar-se pesquisador, o destaque às metodologias participativas, à avaliação por parecer descritivo e o fato das disciplinas terem o mesmo tempo no currículo.

Palavras Chaves: Educação Ambiental; Pesquisa Participante; Relação Teoria e Prática.

\section{ABSTRACT}

This work seeks to check the effects of participation research in the making of a curriculum and pedagogical practices in school environment at Escola Estadual de Ensino Médio Paulo Freire. Thus, the following specific goals are to be analyzed: discuss the concepts of Environment Education adopted by Brazilian Education managers; describe the historical/social context that contributed for the school to choose the participation research methodology and to present the view of teachers that took part in the preparation of the PPP about the effects of the participation research in the making of the curriculum and the pedagogical practices in Environment Education. The research was done using the quality bibliographic method. The investigation showed that that there is a great gap between the pedagogical message and the educational practice, as well as what meaningful changes in education need structural and financial support of the managers. On 
the other hand, some advances in the every day activities of the school investigated were found, as for example: the understanding of the environment education concept as inter-curricular, the understanding of the need to contribute to the formation of citizenship, the recognition of the importance of knowing the reality of the student, the understanding of the need to contextualize local problems and try to solve them, the perception of the importance of a teacher becoming a researcher, the highlight of participation methodologies, the evaluation of a descriptive statement and the fact that the subjects have the same time in the curriculum.

Keys Words: Environmental education; Participant Research; Value Theory and Practice.

\section{INTRODUÇÃO}

A Educação Ambiental (E.A.) é um dos temas mais recorrentes na atualidade. Uma das justificativas para tal preocupação é a percepção de que se o modelo de desenvolvimento, bem como as relações entre os seres humanos, e destes com o meio ambiente, não forem modificados a vida no planeta ficará cada vez mais difícil: espécies de plantas e animais serão extintas, as catástrofes ambientais serão cada vez mais intensas, a fome e as doenças se espalharão pela terra e a pobreza aumentará.

Neste contexto, estudiosos como Carlos Frederico B. Loureiro (2005), Mauro Guimarães (2005), Pedro Roberto Jacobi (2007) e Marilia Freitas Tozoni - Reis (2007) propõem que a E.A. seja orientada por uma visão complexa, transdisciplinar, participativa e crítica, a fim de que os educandos desenvolvam a capacidade de solucionar problemas, construir conhecimentos, compreender as múltiplas relações de todos os aspectos da vida e, principalmente para que desenvolvam a compaixão e a cidadania. Notadamente, associam Educação Popular à E.A. Tal vínculo é destacado nas publicações do Ministério do Meio Ambiente (MMA) e assume uma dimensão importante já que se trata do órgão encarregado de elaborar e divulgar as diretrizes para a E.A. no Brasil (LAYRARGUES, 2004).

Referente à metodologia para efetivar os objetivos da Educação Popular e da E.A., os mencionados autores destacam a Pesquisa Participante (PP).

Neste trabalho, procuraremos investigar os efeitos da PP na construção do currículo e da metodologia em Educação Ambiental na Escola Estadual de Ensino Médio Paulo Freire, localizada em Panambi/Região Noroeste Colonial do Rio Grande do Sul.

A Escola Estadual de Ensino Médio Paulo Freire optou pela metodologia da PP em meio a um contexto de reestruturação curricular orientado pela secretaria de Educação do Estado do Rio Grande do Sul, denominado "Constituinte Escolar". ${ }^{2}$ A maioria dos educadores do

\footnotetext{
${ }^{2}$ A Constituinte Escolar (1999-2002) foi um movimento organizado pela Secretaria de Educação/RS. No primeiro momento a comunidade escolar foi chamada à participação. Posteriormente, realizou-se um estudo da realidade escolar, bem como uma análise das práticas pedagógicas dos educadores gaúchos. O terceiro momento foi o de aprofundamento das temáticas e de devolução das sistematizações, e foi marcado por 31 seminários regionais de sistematização. Em um quarto momento, com a participação dos pais e alunos, foram feitas as definições dos princípios e das diretrizes. Em 2001 aconteceu o quinto momento, marcado pela construção e implementação dos PPPs (Projetos políticopedagógicos), do Regimento e pela Reorganização Curricular à luz das definições dos Princípios e Diretrizes. A intenção dessa reconstrução curricular era que fosse feita a partir da realidade contextualizada historicamente,
} 


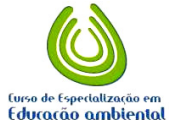

REMOA

estabelecimento de ensino era favorável às pedagogias que contribuíssem com a construção da cidadania. Para tanto, enfatizavam a necessidade de romper com o pensamento cartesiano e com a educação tradicional. Deste modo, os pressupostos teórico-metodológicos que embasaram a proposta foram os da pedagogia crítica.

A instituição de ensino iniciou seus trabalhos em março de 2000. Atende, principalmente, alunos do Bairro Esperança. Atualmente possui 40 professores, 3 funcionários responsáveis pela limpeza e 6 distribuídos nos demais setores. Quanto ao número de alunos, no turno da manhã são 230; à tarde 103 e à noite $202 .^{3}$

A importância da pesquisa consiste no fato de apresentar uma investigação a respeito dos efeitos de um discurso pedagógico vinculado às políticas educacionais no cotidiano de um grupo de educadores, bem como por apresentar suas reflexões a respeito do cotidiano escolar.

\section{OBJETIVOS}

O objetivo geral deste trabalho foi verificar os efeitos da PP na construção do currículo e das práticas pedagógicas em E.A. na escola Estadual de Ensino Médio Paulo Freire.

\section{Objetivos específicos}

- Discorrer a respeito das concepções de E.A. defendidas pelos gestores brasileiros;

- Descrever o contexto histórico/social que contribuiu para que a escola optasse pelo uso da metodologia da PP;

- Apresentar a visão dos professores que participaram da elaboração do Projeto Político Pedagógico (PPP) a respeito dos efeitos da PP na construção do currículo e das práticas pedagógicas em E.A.

\section{ABORDAGEM METODOLÓGICA}

A partir dos objetivos propostos, buscamos desenvolver relações teórico-práticas pertinentes no âmbito desta pesquisa, a partir de uma abordagem investigativa de cunho qualitativo.

\section{Etapas da pesquisa}

Inicialmente, realizou-se uma revisão bibliográfica, incluindo-se a análise do Projeto Político Pedagógico da Escola Estadual de Ensino Médio Paulo Freire. Também se realizou entrevistas com educadores da escola, os quais solicitaram que sua verdadeira identidade fosse

valorizando o saber popular, articulado-o ao saber científico e possibilitando a socialização de experiências (DAL MORO, 2009).

${ }^{3}$ Dados disponíveis na secretaria da Escola Estadual de Ensino Médio Paulo Freire. 
mantida em sigilo, o que nos levou a criar nomes fictícios para as pessoas que citaram durante as entrevistas.

Os critérios para seleção dos entrevistados foi o fato de terem participado da construção do PPP que instituiu a metodologia da PP na escola, bem como por terem permanecido trabalhando na escola. Portanto, em síntese, o trabalho constitui-se de uma visão destes profissionais a respeito dos efeitos do referido projeto em sua prática educativa.

É interessante destacar que dos sessenta educadores ${ }^{4}$ que participaram dos trabalhos iniciais, dez ainda exercem funções na escola. Destes, oito se dispuseram a contribuir com a pesquisa. Todos assinaram um termo autorizando o uso de sua entrevista nesse trabalho.

As questões propostas aos entrevistados foram as seguintes: 1) Explique como aconteceu o processo no qual a escola optou por utilizar a metodologia da pesquisa participante; 2) Por que a comunidade escolar optou por esta metodologia? 3) Qual o referencial teórico que embasa a pesquisa participante na escola? Explique. 4) Explique como é realizada a pesquisa participante na escola? 5) Como, a partir da pesquisa a comunidade escolar elabora o currículo e as atividades metodológicas? 6) Explique como ocorreu o processo de envolvimento da comunidade escolar na pesquisa participante? 7) Quais os temas desenvolvidos relacionados às questões ambientais? 8) Quais as atividades metodológicas desenvolvidas relacionados às questões ambientais? 9) Como ocorre o processo de avaliação desta metodologia na escola? 10) Na sua opinião, o uso desta metodologia produziu mudanças na escola e na comunidade? Quais? 11) Na sua opinião, quais os aspectos positivos e negativos da opção da escola pela metodologia da Pesquisa Participante?

\section{REFERENCIAL TEÓRICO}

Segundo as obras publicadas pelo Ministério do Meio Ambiente (LAYRARGUES, 2004 e FERRARO JUNIOR, 2005), a Crise Ambiental pode ser relacionada à crise da modernidade, ${ }^{5}$ a qual engloba a denomina crise paradigmática do conhecimento e consiste basicamente na percepção das limitações do modelo moderno, caracterizado especialmente pelo pensamento cartesiano, mecanicista. ${ }^{6}$

O modelo moderno fragmentou o conhecimento científico e o colocou como verdade universal. Da mesma forma, defendia que apenas a ciência poderia trazer o desenvolvimento às sociedades humanas, bem como vinculava a idéia de progresso material ilimitado à qualidade de vida (TOURAINE, 1994, p. 9 - 20).

Tais concepções começam a ruir com as descobertas, especialmente, da Física Moderna. Então emerge com grande força o paradigma da complexidade. Seus conceitos contrapõem-se aos princípios cartesianos de fragmentação do conhecimento e propõem outra forma de pensar os problemas contemporâneos (CAPRA, 1996).

\footnotetext{
${ }^{4}$ Segundo Trombetta (2003, p.59), em 2001 havia 680 alunos matriculados na escola.

5 "Modernidade" é um dos termos-chave nas discussões a respeito das temáticas sociais. De forma geral, compreende os padrões de relações sociais, políticas e econômicas, além das próprias configurações culturais, que vieram a se consolidar gradualmente com o declínio das sociedades européias medievais. Dois dos eventos que marcaram a emergência da era moderna foram a Revolução Industrial inglesa e a Revolução Francesa, ambas no final do século XVIII (HOBSBAWM, 1989).

"O termo "mecanicismo" consiste em uma metáfora da realidade como sendo uma máquina, por exemplo: o corpo humano é uma máquina perfeita (CAPRA, 1982).
} 
Para Morin (apud VIÉGA, 2005, p. 175-187), se no cartesianismo o todo é inferior à soma das partes, na complexidade o todo é, ao mesmo tempo, superior, inferior e diferente da soma das partes. Assim, há complexidade quando elementos diferentes são inseparáveis constitutivos do todo, como o econômico, o político, o sociológico, o psicológico, o afetivo e o mitológico (MORIN apud QUINTAS, 2004, p. 137). Por isso a complexidade é a união, entre a unidade e a multiplicidade. Desta forma, a educação deve promover a "inteligência geral" apta a referir-se ao complexo, ao contexto, de modo multidimensional e dentro da concepção global" (Quintas, 2004, p. 137).

Quanto à Educação Ambiental, uma das observações mais destacadas é a de que é impossível explicarmos/compreendermos os problemas sócio-ambientais dentro do paradigma cartesiano (SANTOS, 2008). Layrargues (2004, p.7) explica:

$\mathrm{O}$ adjetivo ambiental designa uma classe de características que qualificam essa prática educativa, diante desta crise ambiental que ora o mundo vivencia. Entre essas características, está o reconhecimento de que a Educação tradicionalmente tem sido não sustentável, tal quais os demais sistemas sociais, e que para permitir a transição societária rumo à sustentabilidade, precisa ser reformulado.

Para Guimarães (2004, p.28), um dos pilares básicos que referencia essa E.A. encontra-se na Teoria Crítica:

A E.A. Crítica objetiva promover ambientes educativos de mobilização desses processos de intervenção sobre a realidade e seus problemas socioambientais, para que possamos nestes ambientes propiciar um processo educativo, superar as armadilhas paradigmáticas em que nesse exercício, estejamos, educandos e educadores, nos formando e contribuindo, pelo exercício de uma cidadania ativa, na transformação da grave crise socioambiental que vivenciamos todos.

Segundo Lima (2004, p.94), em termos teóricos e conceituais a E.A. critica procura enfatizar e associar as noções de mudança social e cultural, de emancipação/libertação individual e social e de integração no sentido de complexidade:

A idéia de mudança social reflete, em primeiro lugar, uma insatisfação ou inconformismo com o estado atual do mundo, com as relações sociais que os indivíduos estabelecem entre si, com as relações dos indivíduos consigo mesmos e com as relações que estabelecem com o seu meio ambiente. Parte da consideração de que essas relações são socialmente injustas, ecologicamente insustentáveis, economicamente deterministas, politicamente não-democráticas, eticamente utilitárias e existencialmente propensas à heteronomia e que podem ser transformadas em direção contrária.

Essa concepção libertária de educação emana de Paulo Freire, o qual vê o "ser humano" como um "ser inacabado", que age para conhecer e transformar o mundo e, ao transformar, se integra e conhece a sociedade (LOUREIRO, 2004, p.67). Em seguida, algumas formulações que expressam possíveis pretensões de uma E.A. crítica (Loureiro, 2004, p. 21):

- Promover a compreensão dos problemas socioambientais em suas múltiplas dimensões, considerando o ambiente como o conjunto das inter-relações que se estabelecem entre o mundo natural e o mundo social, mediado por saberes locais e tradicionais, além dos científicos;

- Contribuir para a transformação dos atuais padrões de uso e distribuição dos bens ambientais em direção à formas sustentáveis, justas e solidárias de vida e de relação com a natureza; 
- Formar uma atitude ecológica dotada de sensibilidades estéticas,
éticas e políticas sensíveis à identificação e resolução dos problemas
e conflitos que afetam o ambiente em que vivemos;
- Atuar no cotidiano escolar e não escolar, provocando novas
questões, situações de aprendizagem e desafios para a participação
na resolução de problemas, buscando articular a escola com os
ambientes locais e regionais onde está inserida;
- Construir processos de aprendizagem significativa, conectando a
experiência e os repertórios já existentes com questões e
experiências que possam gerar novos conceitos e significados para
quem se abre à aventura de compreender e se deixar surpreender
pelo mundo que o cerca;
- Está focada nas pedagogias problematizadoras do concreto vivido,
no reconhecimento das diferentes necessidades, interesses e modos
de relações na natureza que definem os grupos sociais e olugar"
ocupado por estes em sociedade, como meio para se buscar novas
sínteses que indiquem caminhos democráticos, sustentáveis e justos
para todos.
- Baseia-se no princípio de que as certezas são relativas; na crítica e
autocrítica constante e na ação política como forma de se
estabelecer movimentos emancipatórios e de transformação social
que possibilitem o estabelecimento de novos patamares de relações
na natureza.
- Busca redefinir o modo como nos relacionamos conosco, com as
demais espécies e com o planeta. Por isso é vista como um processo
de politização e publicização da problemática ambiental por meio do
qual o indivíduo, em grupos sociais, se transforma e à realidade. Aqui
não cabe nenhuma forma de dissociação entre teoria e prática;
subjetividade e objetividade; simbólico e material; ciência e cultura
popular; natural e cultural; sociedade e ambiente.
- Em termos de procedimentos metodológicos, tem na participação e
no exercício da cidadania, princípios para a definição democrática de
quais são as relações adequadas ou vistas como sustentáveis à vida
plantexto histórico.

Quadro 2: Pretensões da Educação Ambiental

Quanto à metodologia capaz de dar conta de tais pretensões, as obras publicadas pelo Ministério do Meio Ambiente indicam a Pesquisa Participante. 


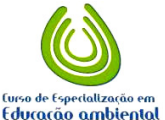

REMOA

A Pesquisa Participante consiste num enfoque de investigação social por meio do qual se busca a participação da comunidade na análise de sua própria realidade, com o objetivo de promover a participação social e a construção do conhecimento (BRANDÃO, 1999). De forma geral, pretende promover a reunião de educadores, pais, funcionários, comunidade e alunos, a fim de identificar os principais problemas da localidade, estudá-los e propor alternativas de solução, pois se acredita que esta prática participativa, além de produzir conhecimento, poderia ser um exercício de cidadania no qual os envolvidos, gradativamente, "aprenderiam" a interferir na sociedade e a exigir seus direitos.

\section{A elaboração do PPP que incorporou a Pesquisa Participante como metodologia}

A construção do Projeto Político Pedagógico (PPP) na Escola Estadual de Ensino Médio Paulo Freire foi fortemente influenciada pelo contexto social no qual a escola estava inserida. Especialmente pelo fato de atender alunos de um dos bairros da periferia de Panambi e por vincular-se à Constituinte Escolar.

Tal relação dava-se porque os professores envolvidos na elaboração do PPP avaliavam que, de forma geral, a educação ministrada no Estado era tradicional e, portanto não serviria para construir cidadania. Seguindo Santiago (1994, p. 599) questionavam: "Qual é o modelo de escola que temos?", para responder em seguida: "Temos uma instituição fundamentada no paradigma da ciência positivista, com um currículo linear, compartimentalizado em disciplinas isoladas e conteúdos fragmentados (...) se fez do professor um técnico 'treinado' para o manejo de classe, excluindo-o da tarefa de pensar e planejar a ação educativa na sua dimensão de totalidade". Acreditavam também que seus alunos, por serem oriundos de um bairro pobre, precisavam de uma metodologia diferenciada para tornar os conhecimentos científicos significativos. 0 Entrevistado 2 recorda,

houve a necessidade de se criar aqui em Panambi uma escola diferente das que estavam atuando no município. Então o grupo de professores da época pensou em fazer alguma coisa que pudesse mudar a realidade dos alunos (...) a metodologia encontrada, com respaldo do governo da época, foi a PP. O objetivo era conhecer nossos alunos e depois de ter o conhecimento dessa realidade, de saber como eles vivem, como eles convivem, traçar uma metodologia de trabalho para a Escola Paulo Freire.

Para alguns dos entrevistados, além da Constituinte Escolar, a proposta de educação popular do município de Porto Alegre também influenciou a construção do PPP.

Entrevistado 1 analisa,

se tu for comparar, as duas coisas são a mesma, por causa do projeto do governo. A teoria é a mesma... Só que a Constituinte Escolar era uma coisa para pensar e o projeto de Porto Alegre já estava pensado. Eu acho que a Constituinte era mais para tentar levar as escolas para aquele lado... por isso que as duas se fundem...

Desta forma, os conceitos que embasaram a construção do PPP foram os da Pedagogia Crítica, defendidos pela Constituinte Escolar e incorporados pelas publicações da MMA.

\section{A construção do currículo}

Seguindo os princípios do PPP, a construção do currículo na Escola Estadual de Ensino Médio Paulo Freire inicia com a PP. Para o Entrevistado 1, o objetivo da metodologia é "ir na 
comunidade, buscar lá os problemas, ouvir as falas, voltar, fazer o estudo, criar alternativas para resolver os problemas".

Sobre como a pesquisa é realizada atualmente, o Entrevistado 4 explica,

Primeiramente, todo início de ano se faz uma reunião geral e se conversa a respeito do que é e a importância da pesquisa (...). Teve ano que elaboramos questionário e anos que preferimos realizar uma conversa informal. Conversávamos sobre o cotidiano: emprego, família, enfim... Depois que é definido como a gente vai fazer a pesquisa, os professores visitam algumas casas. Coletam aquelas frases que são mais significativas... Quando retornamos, dividimos o material coletado. Mas aí, professores que não conhecem o contexto daquela entrevista, escolhem o que na visão deles é mais significativo.

Para o Entrevistado 7,

A PP, no meu modo de ver, desacomoda o professor. Se a gente permanecer no tradicional está tudo prontinho, tudo certinho. Essa nova metodologia exige que o professor tenha que pesquisar, tenha que buscar, então essa é a diferença, ela desacomoda. (...) Eu acho que esse é o ponto positivo: mexe com a estrutura não só da escola, como dos professores. É uma forma nova de trabalhar, tu não tens aquela segurança de ir para sala, tu vai ter que primeiro verificar uma forma diferente de trabalhar o conteúdo.

\section{A participação da comunidade escolar na Pesquisa Participante}

A E.A. defendida no Plano Político Pedagógico (2006, p.18) da Escola Estadual de Ensino Médio Paulo Freire procura romper com as fronteiras entre escola e comunidade. Considera-se o que acontece dentro e fora da escola a fim de se criar processos colaborativos de resolução de problemas locais associados com a crise ambiental em escala planetária. Todavia, a construção desta participação no cotidiano escolar nos parece bastante complicada.

Conforme o Entrevistado 4: "a pesquisa é participativa, mas dificilmente se envolve todos os segmentos da escola. Tipo, nem as serventes, nem as funcionárias, alunos, família, ninguém participa, só são os professores". Para o Entrevistado 3,

\footnotetext{
é participante para os pais e alunos até certo ponto. Também não sei como poderíamos envolver a todos na escolha (das falas), porque seria muita gente... Talvez escolher segmentos de alunos, de pais. Outra coisa que me deixa um pouco desanimada é a questão das ações... Às vezes a gente se propõe a tanta coisa no planejamento, mas chega no final do ano e você vê que deixou bastante a desejar.
}

Para alguns entrevistados, um aspecto que deveria ser considerado é a avaliação da PP. Para estes professores é muito difícil avançar na construção do currículo e das práticas pedagógicas, sem avaliar o trabalho que já foi realizado. Conforme o Entrevistado 5 ,

No começo do ano tem todo aquele: vamos fazer a pesquisa! Três dias correndo, conversando com as pessoas, reuniões... (...) E o que a gente trabalhou há cinco anos atrás não é resgatado nunca! Não é uma coisa que tem continuidade! (...) Assim parece que começa e nunca termina! Por isso que a gente não sai do chão! A gente não deveria parar um dia para discutir?

Segundo o Entrevistado 7, entre os problemas para viabilizar o Projeto Político Pedagógico esta a redução do espaço para reuniões de formação e o aumento do número de professores na escola: 
no início o grupo era menor, a gente tinha condição de fazer formação. Hoje, como o grupo cresceu bastante, nós perdemos essa formação (...). Hoje a escola esta bastante separada por turnos em função dos professores atuarem em mais escolas. A gente não consegue mais sentar com o grupo todo. (...). Não existem mais aquelas reuniões que fazíamos várias vezes ao ano. (...) O dia a dia faz com que o professor tenha que dar conta do jeito dele. Não consegue conversar com o colega... Então um dos entraves é esse. Ultimamente está se tirando horas ao invés de dar, em função de política educacional Estadual. Então esse é o principal entrave que eu vejo, não tem esse espaço coletivo.

Para o Entrevistado 1,

Os professores não sabem o que fazer (...) A gente não sabe mais e agora ainda piorou devido às provas externas. Antes a gente não tinha essa idéia de ficar trabalhando conteúdos. Trabalhava os conteúdos, mas os que eram importantes para analisar aquela linha que a gente estava pesquisando. Só que agora tem uma avaliação externa e a nossa escola está de mal a pior. Então tem uma cobrança. Agora mudou o governo e não se pensa mais do mesmo jeito, a nossa escola está nadando contra a correnteza. Então nós estamos tendo pressão de tudo quanto é lado. Não sabemos se vamos pela proposta ou se trabalhamos só conteúdos para irmos bem nas avaliações externas. Porque se não formos bem na avaliação externa, haverá penalizações. A gente não sabe mais pra que lado correr.

O Entrevistado 4 sintetiza, "na verdade eu acho que a gente ainda tá tentando construir um caminho... E às vezes, falta suporte, falta apoio".

\section{A escolha dos conteúdos}

De acordo com os entrevistados, a escolha dos conteúdos acontece da seguinte forma: inicialmente realiza-se a PP; em seguida, ocorre a análise das falas, conforme critérios definidos pelo grupo. Geralmente consideram-se as que expressam contradições e as que se referem às questões culturais, econômicas e sociais. Após a escolha do tema, que consiste no problema a ser analisado, os professores definem o que chamam de contra-tema. O contra-tema consiste numa hipótese de solução para o problema levantado. Por fim, os educadores produzem uma teia de relações, a chamada Rede Temática, nas quais estão expressos os conceitos que acreditam ser fundamentais para a superação do problema.

Teoricamente, a partir destes conceitos, do tema e do contra-tema os professores selecionariam os conteúdos. De acordo com os entrevistados, o objetivo é de que os conteúdos possibilitassem a compreensão dos problemas locais, bem como sua contextualização. Todavia, segundo Entrevistado 3,

na verdade o que a gente lê e vê sobre pesquisa é que os conteúdos devem partir da pesquisa. Eu, uma vez até tentei fazer assim, mas virou uma bagunça na minha cabeça! Uma bagunça de conteúdos porque dependiam do tema gerador. Por exemplo, para dar conta de determinado tema, precisava estudar a Revolução Industrial com todas as turmas, mas a Revolução Industrial, digamos, era um conteúdo do Segundo Ano do Ensino Médio. Então trabalhava com todos, mesmo que já tivesse trabalhado com o segundo no segundo, trabalhava de novo.

Assim, alguns entrevistados mencionam certa dificuldade ao colocar em prática a metodologia. Uma destas dificuldades refere-se aos conteúdos selecionados para trabalhar a problemática do tema. Conforme o Entrevistado 3, muitas vezes os conteúdos acabam se repetindo ao longo do Ensino Fundamental, 
Aí os alunos diziam: "ah, isso nos já trabalhamos"... Tornava-se um pouco maçante... Tu fazia relações, mas sentia necessidade de trabalhar de novo aqueles conteúdos para ressignificar melhor... Outro problema é que alguns conteúdos são pré-requisito. Tu só pode trabalhar esse conteúdo se já trabalhou com outro anteriormente. Por exemplo, tu chegar com a Revolução Industrial de repente, se ainda não tinha trabalhado, se estava trabalhando com eles os povos antigos, eles não iam entender direito...

Outro problema levantado pelos professores diz respeito ao fato de muitos alunos desejarem trabalhar os conteúdos conforme as demais escolas do município, as quais seguem listas de conteúdos.

na verdade eles querem ver aqueles outros assuntos que as outras escolas trabalham. Sabe, junto com essa história do projeto veio a questão do bairro ser excluído, das pessoas serem excluídas. Então, para alguns ficou a ideia: já que eles são excluídos e burrinhos então vamos trabalhar qualquer coisa. Então na visão deles é isso. Nós temos as melhores das boas intenções, de conscientizar, fazer eles se apropriarem dos problemas deles e irem em busca de solução. Mas eles vêem ao contrário, eles tão enxergando que a gente considera eles burrinhos (Entrevistado 1).

Também as avaliações externas,

essa questão de você dar bastante prioridade pro contexto social, para a realidade do aluno e não conseguir trabalhar os conteúdos, aí as vezes você vê que os nossos alunos vão mal nas avaliações externas. Aí você acaba se perguntando, será que é por que trabalho mais com a relação entre local e global... (Entrevistado 3).

Alusivo à relação entre a lista de conteúdos e a PP, o Entrevistado 2 esclarece: "Tem o programa para cada série. Só que cada professor tem que analisar a partir do contratema a forma que vai trabalhar esse conteúdo, relacioná-lo com o contratema da escola para que os problemas que diagnosticamos possam ser sanados".

O Entrevistado 3 explica: "quando a gente começa com o tema já passou mais ou menos um mês de aula, tu já está trabalhando com os conteúdos então é puxar conteúdos que tu pode trabalhar, relacionando eles com o tema".

Para o Entrevistado 4,

Nas séries iniciais até é fácil trabalhar esta questão porque tu tens aqueles conteúdos: leitura, escrita... é fácil trabalhar o tema, os conceitos... Agora, nas outras séries, principalmente no Ensino Médio é bem complicado... Porque tu sabe que tem aqueles conteúdos para vencer e nem sempre tu consegue relacionar com a pesquisa. Nas séries iniciais tu consegue trazer temas para debater, mas aí o que acontece é que eles não têm muita maturidade para alguns temas, como os sociais. Pra eles muitas vezes é bem estranho... tu trabalha um tema, mas parece que não é da realidade deles, tu sabe que acontece ali, mas parece que não faz parte do dia a dia deles....

E conclui,

a partir da pesquisa, do tema, não se elabora novos conteúdos. Tem aqueles conteúdos que são considerados básicos para cada ano e é trabalhado a partir daquilo. A pesquisa é trabalhada em momentos, não todos os dias em sala de aula. Não é sempre não. Tu pega a lista de conteúdos ( Entrevistado 4).

\section{Para o Entrevistado 5,}

Os livros didáticos mandados pelo governo é que regem as nossas aulas e não a PP. Não consigo ver muitos buscando, são poucos. O que vejo são os livros didáticos abertos dentro das salas de aula e os alunos copiando os conteúdos de lá... O pessoal usa direto. 
O Entrevistado 3 acrescenta,

falta fazer um trabalho interdisciplinar, trabalhar junto as áreas. Eu consegui pouco, com uma ou duas áreas só. Dizer que a escola fez um trabalho com todas as áreas, infelizmente não... Eu acho que nunca aconteceu. Trabalhamos cada um fazendo suas atividades...

De forma geral, podemos perceber dois problemas para efetivar a interdisciplinaridade: não há espaço para formação continuada e, talvez em decorrência disto, não exista uma fundamentação teórica clara a respeito de como esta interdisciplinaridade seria viabilizada a partir dos temas levantados pela pesquisa. O Entrevistado 5 explica: "Os professores estão muito desmotivados para buscar um referencial teórico... porque se a gente soubesse mais, se a gente entendesse mais, talvez a gente ia fazer"...

Por outro lado, o Entrevistado 2 menciona dois aspectos do projeto que considera fundamentais para a construção de um currículo crítico e de novas práticas pedagógicas. Novamente evidencia-se que teoricamente os rumos da escola são progressistas.

\footnotetext{
O fato da escola já não quantificar em números o conhecimento do aluno, não transferir para um boletim meramente números, estatísticas: que ele sabe 80 por cento, 70 por cento, 30 por cento. Eu acho que é muito significativo. Pensar no aluno como um todo. $O$ fato de termos organizado a nossa escola também numa grade curricular na qual as disciplinas tem a mesma importância. Sabemos que na maioria das escolas as ciências exatas têm um peço maior, tem quatro, cinco aulas semanais, enquanto história, geografia, tem uma ou duas. Nós procuramos valorizar todas as disciplinas. Se pegar a nossa grade curricular tu vai ver que no máximo português tem uma aula a mais e matemática, as demais disciplinas têm a mesma carga horária. (Entrevistado 2).
}

Assim, percebe-se que os educadores procuraram implementar as orientações do PPP em seu cotidiano. Houve tentativas de se conhecer a realidade dos educandos e a partir dela elaborar e o currículo. Da mesma forma, procurou-se efetivar metodologias participativas e abordagens que levassem a uma compreensão crítica da sociedade. Todavia, os educadores encontraram diversos obstáculos para efetivar a proposta: a maioria não consegue relacionar os aspectos teóricos com a prática pedagógica e não houve espaço para avaliar suas experiências, nem para formação. Assim, é importante destacar que a falta de espaço para formação esta estritamente relacionada com a atual política de educação, a qual diminui o tempo destinado a formação dos educadores.

\section{O conceito de Educação Ambiental}

Como se percebe, a relação entre a teoria e prática é tensa. O cotidiano, por ser complexo, evidencia uma série de problemas, como os mencionados pelos professores. Todavia, nos parece que mesmo quando as práticas não alcançam os objetivos desejados pelos professores, o fato de mudarem o olhar sobre a educação contribui para a construção de novas aprendizagens, as quais gradativamente podem ou não ser vinculadas às práticas pedagógicas. É o caso da percepção da importância de se compreender a realidade na qual o aluno está inserido e de se perceber que os conteúdos estão relacionados, como atesta o conceito de E.A. do Entrevistado 6,

as falas (selecionadas a partir da Pesquisa Participante) geralmente envolvem todo o contexto e um contexto do que? Saúde, meio ambiente... Porque o ser humano não é um pedacinho! Nós não somos pedacinhos! Eu to falando agora numa visão holística... (...) se eu falo de lixo, eu não to falando lixo. Eu to falando lixo como saúde, mas eu estou falando 
lixo como economia. Eu estou falando lixo como social porque perpassa toda uma vida social do planeta, o lixo está me levando ao amoroso... ao todo.

O Entrevistado 1 reitera: “o ambiente faz parte, porque 'faz parte de tudo', da economia, política, sociedade, da desigualdade" .

Para o Entrevistado 7,

A E.A. não pode ser trabalhada isoladamente e sim, em todas as áreas. Para não ficar a responsabilidade só de um, envolver a todos, procurar dar um subsídio científico e a partir daí tentar ver o que cada um pode fazer na escola, no bairro, no convívio das pessoas o que cada um pode fazer e não deixar o assunto só para uma área, mas sim um todo! Para ligar! Esse assunto da para ligar em todas as disciplinas, trazer informações da problemática. Muitas vezes a gente só coloca a problemática, mas também encontrar soluções, procurar ideias de como atacar essa questão que hoje está na mídia em função das possíveis problemáticas, não está comprovado, mas que se continuar nesse ritmo o que pode vir acontecer ao ser humano no planeta .

\section{A construção das práticas pedagógicas em Educação Ambiental}

As práticas pedagógicas em E.A. descritas pelos professores são norteadas por alguns pressupostos. Dentre estes, destaca-se a compreensão da necessidade dos alunos construírem uma preocupação com o futuro, como explicou o Entrevistado 5,

Eu acho que a gente deveria estudar uma forma de conscientização para eles entenderem que, se eles jogarem a $M$ ali hoje, a $M$ vai está ali depois de um ano e eles vão pisar e vão ficar doentes, que eles têm que cuidar, mas as pessoas conseguem ver o futuro! A gente fica assim, num consumo imediato. Hoje eu quero, hoje eu tenho água, tá bom... se amanhã não tiver água, não consigo perceber os males que isso vai trazer... porque a gente vive numa cultura do imediato: eu preciso ter hoje! Se amanhã eu não tiver, amanhã eu penso...?

Outro aspecto é a preocupação com a construção da cidadania,

A cidadania é uma coisa complicada porque os alunos se acham excluídos então acham que não precisam... Acham que não precisam cuidar porque o mundo não é para eles... Eles não se enxergam como sujeitos. Eles acham que o Miguel (prefeito) que tem que ir limpar o rio... Não é a gente que tem que deixar de largar as coisas dentro do rio. Ele que tem que ir ali plantar árvore, não é a gente que tem que ir...

Para o Entrevistado 8, "O princípio básico é consciência, conscientização e ação porque consciência só por si também não gera efeito nenhum. Geralmente em cima das atividades, a gente sempre tenta desenvolver alguma atividade prática".

O Entrevistado 7 destaca: "existe aquela preocupação de tentar desenvolver o senso crítico que é inerente à nossa proposta".

Um dos aspectos que fica evidente na fala dos entrevistados é a compreensão de que a E.A. não é uma disciplina isolada. Está relacionada com todo o currículo. O Entrevistado 7 explica: "Ela tem uma ligação direta com todas as questões de âmbito geral, elas ligam".

Outra preocupação mencionada é a de que os alunos compreendam como o ambiente funciona. O Entrevistado 1 esclarece,

procuro trabalhar atividades que façam eles primeiro compreender como o meio ambiente funciona. Então faço terrário, assim eles vão perceber como os seres vivem. A gente vai investigar na horta, no mato, pra ver se lá também é igual no terrário, porque no 
terrário sua e no ambiente a gente não vê aqueles pingos de água, então eles relacionam com a chuva, trabalho fazendo relações. A sexta série foi trabalhar o bioma onde moramos, aí fomos pesquisar dentro de todos os biomas que tem no Brasil o que nós moramos.

Destaca-se ainda o entendimento de que a compreensão dos assuntos tem caráter interdisciplinar. O Entrevistado 1 explica:

Então fomos pesquisar a Mata Atlântica, eles viram como é, como era lá em 1500. Então a gente relacionou com a história, pegamos livros de história, o que eu menos trabalhei foi com livro de ciências, eu trabalhei com livro de geografia e história pra ver como era em 1500 (...). Na oitava série a gente tenta trabalhar como o nosso estilo de vida afeta o ambiente. Vimos que tem química até no sabonete, que quanto mais colorido mais química tem lá dentro e que pra fazer esse sabonete se precisou recursos naturais, que pra descartar, vai causar muitos danos ambientais. Então estudamos as reações químicas que acontecem para fazer esse descarte.

Outro aspecto mencionado pela professora é a preocupação em relacionar o local com o global. Todavia, o Entrevistado 4 destaca:

Em resultados bem concretos nunca foi conseguido nada, só aquelas pequenas ações isoladas, não se faz um trabalha mais amplo, maior, que envolva toda a escola, toda a comunidade... é mais aquela coisa assim, aquelas atividades tipo, vamos fazer uma campanha de conscientização contra o desperdício da água, ai a gente faz panfleto, faz imã de geladeira, distribui... (Entrevistado 4, Ana, 2009).

Outro problema refere-se ao fato de que no cotidiano escolar, não são todas as áreas que trabalham com as questões ambientais. Conforme o Entrevistado 3,

tu não vê as áreas não voltadas para ciência e pro social trabalhando muito com o tema. Se bem que tinha uma professora de matemática que tinha um projeto para organizar caixas de água, cisternas... até que ela tentou mas não deu certo... então todas as áreas tentaram trabalhar, mas com certeza as áreas das ciência biológicas e algumas sociais trabalham bem mais... isso fica bem claro.

Quanto à metodologia,

As velhas atividades continuam acontecendo... Então os alunos acham que aqueles professores que tentam trabalhar diferente, trabalhar a consciência critica, esses são ruins... porque esses exigem muito... grande parte dos professores na escola faz atividade de completar lacuna, na hora das reuniões eles falam: ah eu faço isso, eu faço aquilo... mas se a gente for de sala em sala (...) o que eu mais percebo é que os professores continuam preenchendo lacuna... (Entrevistado 1)

\section{Para o Entrevistado 5,}

O que rege as nossos aulas é o conteúdo! Não é a transformação, não é o dialogo, não é! Eu acho até que em anos anteriores a gente tinha um entusiasmo maior, mas nos últimos dois, três anos, não tem animo nenhum por parte dos professores pra fazer! Eu não vejo alegria, vontade de fazer, de compartilhar... (...) Eu acho que a gente peca, a gente poderia fazer ações mais práticas... Eu não consigo ver ação concreta nenhuma!Que produza cidadania, que busque transformação... não vejo...(...) Me parece que não há um grande entendimento, nem preocupação em fazer com que haja cidadania. É tudo uma grande confusão!

No entanto, o problema mais recorrente na fala dos entrevistados consiste na dificuldade em relacionar os aspectos teóricos com as práticas educativas. Para Entrevistado 4, a compreensão dos aspectos teóricos é mais recorrente, todavia: "falta a prática e eu acho que a prática é muito mais significativa que o teórico" (Entrevistado 4, Ana, 2009). 
Conforme o Entrevistado 8, alguns professores não conseguem compreender o projeto da escola, especialmente os que chegaram recentemente à instituição: "Não são todos os professores que têm esse conceito já formado. E mesmo para nós que viemos trabalhando desde o início das atividades letivas na escola, inclusive para nós, isso é muito difícil"!

Por outro lado, os professores também mencionam alguns avanços que consideram decorrentes da opção pela metodologia da PP: O Entrevistado 1 destaca a avaliação por parecer descritivo. O Entrevistado 2, o fato das disciplinas terem o mesmo peso no currículo. Já o Entrevistado 7, as relações entre professores alunos: "Na questão relação, eu acho que nós atingimos totalmente o nosso objetivo. Tem melhorado a relação na escola e na própria comunidade."

Para o Entrevistado 3, a preocupação com a construção de relações democráticas,

nem sempre a gente consegue, mas a gente tenta resolver tudo de forma democrática, discutir com eles... A gente constrói todos os anos os princípios de convivência que envolve também essa questão de direitos onde eles escolhem os princípios, eles votam, foi um processo bem importante na escola e que ajudou, cada ano esse construir os princípios de convivência, os alunos participam mais e tem mais consciência e a gente melhora a questão de disciplina na escola e da participação.

Bem como, a compreensão da importância de trabalhar com a realidade dos educandos,

O principal é a importância de se trabalhar com a realidade do aluno, porque na realidade que a gente tinha lá na escola era tanto problema que os alunos tinham no meio deles que se agente não trabalhasse com a realidade não ia significar, eles não iam aprender nada dos conteúdos que a gente tinha para trabalhar com eles (Entrevistado 3).

O Entrevistado 1 destaca dois aspectos. A avaliação,

a gente conseguiu sair da história da nota, pra uma coisa mais avançada que é trabalhar com critérios, com o relatório, que também passou por várias fases e ainda não se tem consenso sobre ele. (...) a gente estabelece critérios, que também ainda tem muitas falhas, mas pelo menos estabelece... então a gente saiu daquilo de medir aluno por nota, cada um é medido segundo seu esforço, sua aprendizagem... que dizer, mais ou menos... Mas já é um avanço... a reprovação quando ela existe tem um conselho de professores no qual é analisado todas as questões do aluno.

E o fato de alguns professores terem se tornado pesquisadores,

Alguns professores foram atrás, em busca... porque a falta leva à busca. Eu acho que isso foi um aspecto positivo. Foram uns quantos que foram atrás de inovação de pesquisa, se atracaram a buscar sozinhos... alguns aprenderam que tem que buscar com Paulo Freire (Entrevistado 1).

Como se percebe, os conteúdos e as concepções de práticas pedagógicas mencionados pelos professores estão de acordo com as discussões nacionais a respeito de E.A. Especialmente sua compreensão de que a E.A. é interdisciplinar e que deve contribuir com a construção da cidadania.

No entanto, ainda existe uma enorme distância entre a teoria e a prática. Para o Entrevistado 6:

Os professores compreendem a pesquisa. Eles sabem a pesquisa, eles estendem a fala... O que falta é construir um currículo, é sistematizar na prática toda esta construção maior no trabalho diário, na construção diária do conhecimento. O currículo em sala de aula é tradicional. (...) A contradição está na hora de trabalhar esse currículo construído. Na hora de sistematizar em sala de aula, ali na prática, do pequeninho, do mínimo, do micro... 


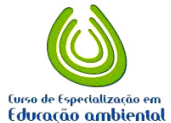

REMOA

Quanto às dificuldades encontradas pelos educadores para efetivar seus conceitos de E.A. no cotidiano escolar, podemos mensurar que está associada à falta de espaço para formação e consequentemente, às políticas educacionais. Assim, quando os gestores se propõem a construir uma educação voltada para a emancipação e cidadania, o tratamento à escola e aos professores é um. Quando a preocupação é cortar verbas, o tratamento é outro.

Desta forma, a construção de uma E.A. realmente comprometida com a mudança das relações entre os seres humanos e destes com o meio ambiente não depende apenas das boas intenções e dos esforços dos professores. Construir uma escola voltada ao enfrentamento dos múltiplos desafios da atual sociedade, demanda o enfrentamento dos próprios desafios colocados no interior de um sistema de ensino fragmentado e baseado em políticas de educação que na maioria das vezes constituem-se como entraves aos processos e práticas educativas de caráter dialógico, autônomo e democrático (FRANCO apud JACOBI; TRISTÃO; GONÇALVES, 2007, p. 77). O Entrevistado 8 sintetiza: "a educação sozinha não transforma o mundo, tem um contexto de sociedade, de valores, cultura. Mas a gente sempre tenta trabalhar para que todos aprendam de fato os seus direitos, os seus valores, porque cada um de nós é importante e é isso que deve prevalecer" (grifo nosso).

\section{CONSIDERAÇÕES FINAIS}

A Educação Ambiental traz como característica o fato de que é preciso mudar a prática pedagógica. O discurso teórico não pode ser desvinculado da prática educativa porque suas problemáticas exigem ações em curto prazo devido a sua urgência. Assim, a teoria deve servir para repensar a prática.

Os depoimentos a respeito da Escola Estadual de Ensino Médio Paulo Freire demonstraram que houveram avanços no cotidiano dos que optaram pela Educação Popular vinculada à E.A., por exemplo: a construção crítica de um conceito de E.A. interdisciplinar, a constatação da importância de se conhecer a realidade do aluno; a compreensão da necessidade de contextualizar os problemas locais, bem como tentar resolvê-los; a compreensão da necessidade da pesquisa como metodologia básica (para alunos e professores) e a importância do professor ser autônomo; a compreensão da importância das metodologias participativas; a compreensão da necessidade de se contribuir com a construção da cidadania; a avaliação por parecer descritivo e o fato das disciplinas terem o mesmo tempo no currículo.

Destarte, destaca-se a compreensão de que entre os aspectos que contribuem para a degradação ambiental e a desigualdade social, estão a falta de políticas públicas e a existência de maus políticos. Desta forma, a construção da cidadania seria um dos problemas centrais da contemporaneidade e a educação ambiental um processo de educação política que possibilitaria a aquisição de conhecimentos e habilidades, bem como a formação de valores e atitudes que poderiam converter-se em práticas de participação cidadã, as quais possibilitariam a construção e manutenção de uma sociedade sustentável.

Deste modo, superar a crise ambiental denota não apenas a troca do modelo econômico atual por um modelo de desenvolvimento sustentável, mas especialmente a mudança na relação dos seres humanos entre si e com a natureza. 
Por outro lado, parece evidente que sem uma infra-estrutura que permita aos professores estudar e se tornarem autores de sua prática educativa, dificilmente construiremos práticas pedagógicas comprometidas com a construção da cidadania.

\section{REFERÊNCIAS BIBLIOGRÁFICAS}

BRANDÃO, Carlos Rodrigues. Repensando a Pesquisa Participante. São Paulo: Brasiliense, 1999.

CAPRA, Fritjof. A teia da vida: uma nova compreensão científica dos sistemas vivos. São Paulo: Cultrix, 1996.

DAL MORO, Selina Maria. O prometido e o realizado: da construção à realização da Constituinte escolar. Disponível em < http://www.isecure.com.br/anpae/410.pdf >. Acesso em: 12 set. de 2009.

FERRARO-JUNIOR, L. A. (Coord.) Encontros e Caminhos: formação de educadoras (es) ambientais e coletivos educadores. Brasília: MMA, Diretoria de Educação Ambiental, 2005.

JACOBI, Pedro Roberto; TRISTÃo, Martha; GONÇALVES, Maria Isabel Correa Franco. A Função social da Educação Ambientais nas práticas colaborativas: Participação e engajamento. Cad. Cedes, Campinas, vol. 29, n. 77, p. 63-79, jan./abr. 2009.

LAYRARGUES, Philippe Pomier (coord.). Identidades da educação ambiental brasileira / Ministério do Meio Ambiente. Diretoria de Educação Ambiental; Brasília: Ministério do Meio Ambiente, 2004.

LIMA, Gustavo Ferreira da Costa. Educação, emancipação e sustentabilidade: em de uma pedagogia libertadora para a defesa ambiental educação. In: LAYRARGUES, Philippe Pomier (coord.). Identidades da educação ambiental brasileira. Ministério do Meio Ambiente. Diretoria de Educação Ambiental; Brasília: Ministério do Meio Ambiente, 2004.

LOUREIRO, Carlos Frederico Bernardo. Educação ambiental transformadora. In: LAYRARGUES, Philippe Pomier (coord.). Identidades da educação ambiental brasileira. Ministério do Meio Ambiente. Diretoria de Educação Ambiental; Brasília: Ministério do Meio Ambiente, 2004.

QUINTAS, José Silva. Educação no processo de gestão ambiental: uma de educação ambiental transformadora e proposta emancipatória. In: LAYRARGUES, Philippe Pomier (coord.). Identidades da educação ambiental brasileira / Ministério do Meio Ambiente. Diretoria de Educação Ambiental; Brasília: Ministério do Meio Ambiente, 2004.

SANTIAGO, Anna Rosa. "Projeto Político-Pedagógico: Escola Básica e a Crise de Paradigmas". In: Conferência Nacional de Educação para Todos. Anais. Brasília: MEC/SEF, 1994.

SANTOS, Akiko. Complexidade e transdisciplinaridade em educação: cinco princípios para resgatar o elo perdido. Revista Brasileira de Educação v. 13 n. 37 jan./abr. 2008.

TOURAINE, Alain. A crítica da modernidade. Petrópolis - RJ: Vozes, 1994.

TOZONI - REIS, Marilia Freitas e Campos (org). A pesquisa-ação-participativa em educação ambiental: reflexões teóricas. São Paulo: Annablume, 2007.

VIÉGA, Aline. Complexidade: uma palavra com muitos sentidos. In: FERRARO-JUNIOR, L. A. (Coord.) Encontros e Caminhos: formação de educadoras (es) ambientais e coletivos educadores. Brasília: Ministério do Meio Ambiente, Diretoria de Educação Ambiental, 2005. 